\title{
Air Quality Analysis in the European Union
}

\author{
M. Dolores Huete-Morales ${ }^{1 *}$, José-Manuel Quesada-Rubio ${ }^{2}$, \\ Esteban Navarrete-Álvarez ${ }^{2}$, M. Jesús Rosales-Moreno², \\ M. José Del-Moral-Ávila ${ }^{2}$ \\ ${ }^{1}$ Department of Statistics and Operations Research, Faculty of Labour Sciences, University of Granada, \\ C/Rector López Argüeta, s/n. 18071 Granada, Spain \\ ${ }^{2}$ Department of Statistics and Operations Research, Faculty of Sciences, University of Granada, \\ Campus de Fuente Nueva, s/n. 18071 Granada, Spain
}

Received: 4 October 2016

Accepted: 4 December 2016

\begin{abstract}
Environmental quality is a characteristic inherent to all ecosystems, and so knowledge of the indicators that define it, within those of sustainability as a whole, is of vital importance. In particular, environmental analysis of any area should include information on air quality together with data on water, soil, natural resources, and human beings. The distribution of individuals and their impact on the environment varies enormously among countries. This paper presents a statistical analysis of the environmental impact recorded in 27 countries of the European Union, taking into account variables relating to the volume of pollutants emitted to the atmosphere, freshwater abstraction, and the population density in each country. A hierarchical cluster analysis has allowed us to establish groups of countries of similar behavior within the considered variables. Countries with anomalous records (above the EU average) have been detected.
\end{abstract}

Keywords: environmental pollution, human factor, statistical analysis, European Union

\section{Introduction}

The European Union (EU) is composed of 28 countries with an estimated population of more than 500 million inhabitants, and covers more than 4 million $\mathrm{km}^{2}$. Of these countries, 17 share a common currency within the Euro Zone, while 11 retain their respective currencies. In addition, a few very small countries, such as the Vatican, do not belong to the EU but have adopted the Euro. At present, five countries (Macedonia, Iceland, Montenegro, Serbia, and Turkey) are official candidates for EU membership.

*e-mail: mdhuete@ugr.es
In 1973 the European Commission drafted the first Environment Action Programme, and 30 years later the EU remained committed to the protection of its environment. Legislation controlling gas emissions has led to significant improvements in air quality. In July 2002 the sixth Environmental Action Programme was approved [1] and a 10-year framework was established for community action on the environment. This was adopted by the European Parliament and remained in force until mid-2012. In November 2010, the seventh Environmental Action Programme [2] replaced the former edition, and representatives from the commission, national governments, the European Parliament, and civil society organizations discussed the policies needed to prevent environmental degradation within the EU and the rest of the world. A United Nations report [3] describes the 
environmental impacts on the Earth resulting from human consumption and production in relation to key products and materials.

Within the European Union, the impact of climate change varies among its member countries; the highest risk areas are in the south (in the Mediterranean basin) while air pollution is much less severe in Scandinavia. Despite these differences in air quality, all EU countries are making great efforts to reduce their emissions from industry, vehicles, power plants, and domestic and agricultural sources [4].

Of the pollutant gases, $\mathrm{CO}_{2}$ is of primary concern. It traps heat, giving rise to the greenhouse effect, and is classified as the gas producing the most impact on air quality in all regions [5]. Its concentration in the air is due to the burning of fossil fuels and to the disappearance of forests and woodland [6]. Another contaminant is sulphur oxide, which as $\mathrm{SO}_{2}$ or $\mathrm{SO}_{3}$ is partially responsible for acid rain and is formed, among other causes, by the combustion of coal and oil, by metalworking, and by volcanic activity. Oxides of nitrogen take the form of nitric oxide, nitrogen dioxide, or nitrous oxide. The first two influence the destruction of the ozone layer and are also involved in acid rain, and are largely caused by vehicle emissions.

Ammonia is another primary pollutant containing nitrogen, although it normally provokes low levels of emissions to the atmosphere. Of the volatile organic compounds, the most abundant is methane, which has a major influence on the greenhouse effect and is emitted into the atmosphere from agricultural and livestock activities, waste treatment, etc. Other volatile organic compounds or hydrocarbons play a significant role in the reactions that cause photochemical smog, and are produced mainly by natural processes.

Several studies have analyzed different types of air pollution in relation to persistent organic pollutants [7] and the effects of economic growth on gas emissions [8]. In the present paper, we analyze the spatial behaviour of the levels of emissions within the European Union, using a geographic information system [9], as has been done in earlier studies involving different spatial areas, usually in urban or metropolitan areas [10-11]. An important consideration is that the great size of the study area the entire EU - complicates both data collection and the management of the variables to be analyzed.

\section{Material and Methods}

For the statistical analysis addressed in this study ${ }^{1}$ we selected a series of variables that influence air quality. First we considered those related to the emissions of polluting gases such as sulphur oxides, nitrogen oxides, ammonia, and non-methane volatile organic compounds [12]. In addition, we took into consideration the population of

Croatia joined the EU on 1 July 2013. The data analyzed in this study had been extracted prior to 2013, so 27 countries were considered. each area, as this factor is a determinant of the level of contamination caused by human action. The population size is a strong indicator of the pollution resulting from development in industry, agriculture, transport, and other sectors. The population data selected were those for 2009 [13]. Furthermore, rainfall gradually cleans the atmosphere and the ground, and so total water extraction ${ }^{2}$ (in millions of $\mathrm{m}^{3}$ ) [14] was taken as a possible impact variable. Data on the area of woodlands and forests ${ }^{3}$ [15] are also useful for measuring the degree of potential air purification. The relationship between degradation of forests and levels of air pollution is well established [16]. In our study, the total surface area [17] of each country was used to weight the above variables and thus standardize the compiled data.

In the analysis of the spatial dimension of the data, the regions are no longer considered as independent geographical bodies in order to incorporate the possibility of spatial interaction [18]. Spatial autocorrelation can be defined in a number of manners: Sokal and Oden [19], Tobler [20], and Upton and Fingleton [21]; following Cliff and Ord [22], it can be defined in this manner: "if the presence of some quantity in a county (sampling unit) makes its presence in neighbouring counties (sampling units) more or less likely, we say that the phenomenon exhibits spatial autocorrelation." Moran's Index [23-24] is commonly employed to measure spatial autocorrelation, calculated via the following equation:

$I=\frac{n}{\sum_{i=1}^{n} \sum_{j=1}^{n} w_{i j}} \frac{\sum_{i=1}^{n} \sum_{j=1}^{n} w_{i j}\left(x_{i-} \bar{x}\right)\left(x_{j}-\bar{x}\right)}{\sum_{i=1}^{n}\left(x_{i}-\bar{x}\right)^{2}}$

... where $n$ is the number of countries and $\mathrm{W}=\left(\mathrm{w}_{\mathrm{ij}}\right)$ is the matrix of spatial weights that determine the degree of contiguity between zones $\mathrm{i}$ and $\mathrm{j}$. In this paper the $\mathrm{w}_{\mathrm{ij}}$ contiguity measurement is considered as the inverse of the distance between capitals in each of the countries analyzed. The values of Moran's index oscillate between +1 (representing a strong positive spatial correlation) and -1 (representing a strong negative spatial correlation), while where no spatial correlation exists the index values will be close to zero.

\section{Results and Discussion}

As can be seen when the information is presented using a geographical information system [25], the population density is quite high in small countries such as Malta

2 Water removed from any freshwater source, either permanently or temporarily. Mine water and drainage water as well as water abstractions from precipitation are included, whereas water used for hydroelectricity generation (in situ use) is excluded.

3 Forest area is land under natural or planted stands of trees of at least $5 \mathrm{~m}$ in situ, whether productive or not, and excludes tree stands in agricultural production systems (for example, in fruit plantations and agroforestry systems) and trees in urban parks and gardens. 
(1,380 inhabitants per $\left.\mathrm{km}^{2}\right)$, the Netherlands (486.2), and Belgium (348.3); the least densely populated countries are Finland (17.5 inhabitants per $\mathrm{km}^{2}$ ) and Sweden (22.6). This situation strongly affects levels of air pollution; thus, Malta recorded the highest levels of all types of air pollution in the EU in 2009, which shows consistency with the environmental problems facing Malta, some of which have been addressed by different institutions, including the European Parliament [26]. Although no data are available for the forested area in Malta, the relationship between population density and forest area is apparent; for the EU as a whole, the value of Pearson's linear correlation coefficient [27] is -0.56 ( $p$-value $=0.003$ ) and these variables are significantly related to pollution levels.

The forest index (calculated as the ratio of forest area to total surface area) is high in Finland (0.726) and Sweden (0.686) and much lower in countries like Ireland (0.106; although here the total forest area has increased by $59 \%$ since 1990), and the Netherlands (0.107). This indicator has increased in all countries since 1990. The average forest index for the EU in 2010 was 0.34 , which represents an increase of $13 \%$ since 1990, indicating that the overall situation in the EU has improved markedly in recent years and that the forestry policies being implemented are proving effective.

The statistics on the recorded emissions of $\mathrm{CO}_{2}$ (in thousands of tons per $\mathrm{km}^{2}$ ) in the EU in 2008 (except for Malta) show that the lowest values were recorded in Sweden (0.146), Latvia (0.147), and Finland (0.208), while the highest were found in the Netherlands (6.101) and Belgium (4.13). The EU average was 1.316. These data for 2008 are not encouraging, when compared with those for 1999; only eight countries reduced their levels of emissions (the best results being those of France, by $6.4 \%$, and Slovakia, by $5.9 \%$ ). In contrast, $\mathrm{CO}_{2}$ emissions rose in Denmark by $42.2 \%$ and in Slovenia by $31 \%$. Overall, the increases in $\mathrm{CO}_{2}$ emissions exceeded the reductions.

The emissions of sulphur oxide also varied widely among the countries surveyed. The lowest values recorded in 2009 corresponded to Latvia ( 0.063 thousand tons per $\mathrm{km}^{2}$ ) and Sweden (0.073), while the highest were found in Malta (24.817), followed at a considerable distance by Bulgaria (5.927) and Greece (3.237). The mean overall of emission level of sulphur oxide was 2.196 (1.326 excluding Malta). The evolution of these emissions over time is, nevertheless, very encouraging, since almost all countries have reduced their emissions since 2000. The reductions have been dramatic in Slovenia (87.48\%), Hungary $(83.69 \%)$, and Ireland $(76.60 \%)$, but less than $20 \%$ in Turkey, Lithuania, and Greece. The exceptions are Romania, where they increased slightly $(0.69 \%)$, and Luxembourg, where although the 2009 values in absolute terms were not very high, they had increased by $1,382 \%$ with respect to the year 2000. Overall, though, the policies adopted by the EU are having a positive effect in terms of reducing emissions of sulphur oxides, with an average reduction for the EU as a whole (excluding Luxembourg) of approximately $48 \%$.
Nitrogen oxide emissions in 2009 also varied widely. The lowest values were recorded in Sweden ( 0.364 thousand tonnes per $\mathrm{km}^{2}$ ), Latvia (0.440), and Finland (0.501), and the highest in Malta (27.083), the Netherlands (8.118), and Belgium and Luxembourg (above 6 in each case). The average level in the EU was 3.534 (2.629 excluding the anomalously high value of Malta). Compared to the year 2000 , overall EU emissions fell by $25.77 \%$, although results were very heterogeneous; levels fell in most countries in comparison with 2000, with the largest reductions in emissions being achieved by the United Kingdom (39.29\%) and the Czech Republic, Belgium, Ireland, Denmark, Italy, and the Netherlands with reductions of over $30 \%$. But levels rose in Luxembourg (with a dramatic increase of $2,083 \%)$, Lithuania $(30.19 \%)$, and Greece (3.37\%).

The average level of ammonia emissions in the EU in 2009 was 1.137 tons per $\mathrm{km}^{2}$ - a reduction of $10.2 \%$ with respect to 2000. Again, Malta recorded the highest value (5.120), followed by the Netherlands (3.691) and Belgium (2.153). Sweden (0.117), Finland (0.120), and Estonia $(0.229)$ reported the lowest rates. Most countries reduced their emissions compared to 2000 - especially in Bulgaria (52.98\%) and the Netherlands $(22.89 \%)$ - and emissions increased in only four countries, with the highest increase being recorded in Latvia (26.34\%).

The mean level of emissions of 'Other compounds' in 2009 was 2.034 tons per $\mathrm{km}^{2}$, which represents a decrease of $29.65 \%$ compared to 2000 . By country, Malta again recorded the highest level at 7.470 , followed by the Netherlands (4.529) and Italy (3.677). Finland (0.365) and Sweden (0.437) recorded the lowest emissions in 2009. Almost all countries managed to reduce their emissions in this respect, except for Bulgaria (increase of $42.40 \%$ ), Romania (28.63\%), and Poland (2.68\%). The reductions were particularly pronounced in France $(48.54 \%)$, Belgium (47.24\%), and the United Kingdom (47.17\%).

The differences in the values of freshwater extraction (in millions of $\mathrm{m}^{3}$ per $\mathrm{km}^{2}, 2009$ or latest available) are also very different between these countries. The Netherlands (0.312), Belgium (0.201), and Malta (0.110)

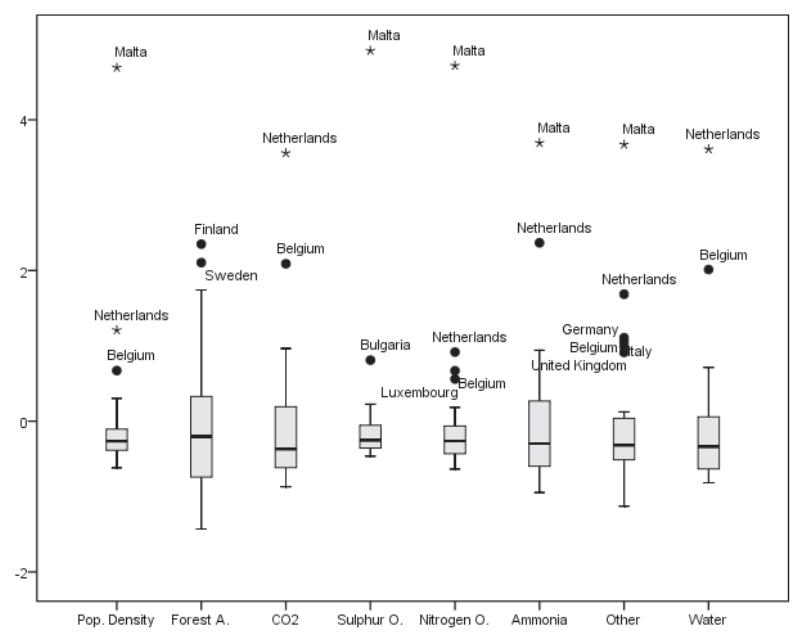

Fig. 1. Box-plot of standard values in the European Union. 
Table 1. Moran's Index and p-values for European Union variables.

\begin{tabular}{|c|c|c|c|c|c|}
\hline & $\begin{array}{c}\mathrm{I}- \\
\text { Moran }\end{array}$ & $\mathrm{E}(\mathrm{I})$ & $\mathrm{V}(\mathrm{I})$ & $\mathrm{z}(\mathrm{I})$ & "p-value \\
\hline $\begin{array}{c}\text { Population } \\
\text { density }\end{array}$ & 0.0159 & -0.0385 & 0.0041 & 0.8479 & 0.3965 \\
\hline Forest area & 0.1397 & -0.0385 & 0.0042 & 2.7526 & $\mathbf{0 . 0 0 5 9}$ \\
\hline $\mathrm{CO}_{2}$ & 0.1339 & -0.0385 & 0.0042 & 2.6730 & $\mathbf{0 . 0 0 7 5}$ \\
\hline Sulphure O. & 0.0140 & -0.0385 & 0.0041 & 0.8196 & 0.4125 \\
\hline Nitrogen O. & 0.0230 & -0.0385 & 0.0041 & 0.9587 & 0.3377 \\
\hline Ammonia & 0.0712 & -0.0385 & 0.0042 & 1.6996 & $\mathbf{0 . 0 8 9 2}$ \\
\hline $\begin{array}{c}\text { Other } \\
\text { compounds }\end{array}$ & 0.0587 & -0.0385 & 0.0042 & 1.5050 & 0.1323 \\
\hline Fresh water & 0.0049 & -0.0385 & 0.0041 & 0.6740 & 0.5003 \\
\hline
\end{tabular}

*p-values less than .1 are highlighted.

recorded the highest values, while Latvia (0.003), Sweden (0.006), and Ireland (0.010) reported the lowest.

The extreme values recorded for all the analyzed variables (Fig. 1) show that Malta and the Netherlands can be considered to show extreme outlier data in the EU, while in many cases Belgium is the 'standard' outlier. These data about Malta, Netherlands, and Belgium are in accordance with those described in the 2015 United Nations annual report [28], which states that concentrations of particulate matter and nitrogen oxides exceed the EU limit values. The evolution of Malta's greenhouse gas emissions is analyzed in [29].

Moran's I statistic for spatial autocorrelation was determined for each variable (Table 1), using the distances between the capitals of each country as weights. This statistic follows a normal asymptotic distribution under the hypothesis of independence of observations, which allows us to construct a test to measure the significance of the spatial autocorrelation [22].
Moran's I statistic determines whether the values of a variable are spatially clustered, dispersed, or are random. It usually takes values in the interval $(-1,1)$. If the values are grouped spatially, the indicator is positive and if they are dispersed it is negative. Values close to zero indicate randomness in the spatial distribution of observations [30]. In our case, the value is positive for all the variables analyzed, although the associated p-value leads us to reject the hypothesis of randomness in the spatial distribution only for the Forest Area, $\mathrm{CO}_{2}$, and Ammonia variables, for which the Index I values are 1.1397, 0.1339, and 0.0712 , respectively.

We make use of the existence of spatial clusters to apply cluster analysis of spatial patterns [31], by which missing values are replaced by the mean of the series. Hierarchical methods are used with the standardised variables (centroid clustering and Euclidean distance in the construction of the distance matrix), and the dendogram (Fig. 2) is obtained using R-project [32].

The first cluster is the largest, and consists of 14 countries: Austria, Bulgaria, Cyprus, Czech Republic, France, Greece, Hungary, Lithuania, Poland, Portugal, Romania, Slovakia, and Spain. The second is comprised of Estonia, Finland, Latvia, Slovenia, and Sweden. The third contains Denmark, Germany, Italy, Luxembourg, and the United Kingdom. Ireland joins the latter at some distance, followed by Belgium, the Netherlands, and especially Malta, at very considerable distances and thus forming isolated clusters: Ireland ( $4^{\text {th }}$ cluster $)$, Belgium $\left(5^{\text {th }}\right.$ cluster $)$, the Netherlands ( $6^{\text {th }}$ cluster), and Malta ( $7^{\text {th }}$ cluster). The centroids of these clusters (Table 2) reveal the differences between them: Cluster No. 1, the most numerous, presents average-level values for all variables; No. 2 presents low values for population density, high ones for forest cover, and low emission rates; while No. 3 has the highest population density, a low forest area, and relatively high levels of emissions. With respect to the countries forming isolated clusters, Belgium and the Netherlands have high values of population density, low levels of forest cover, and high

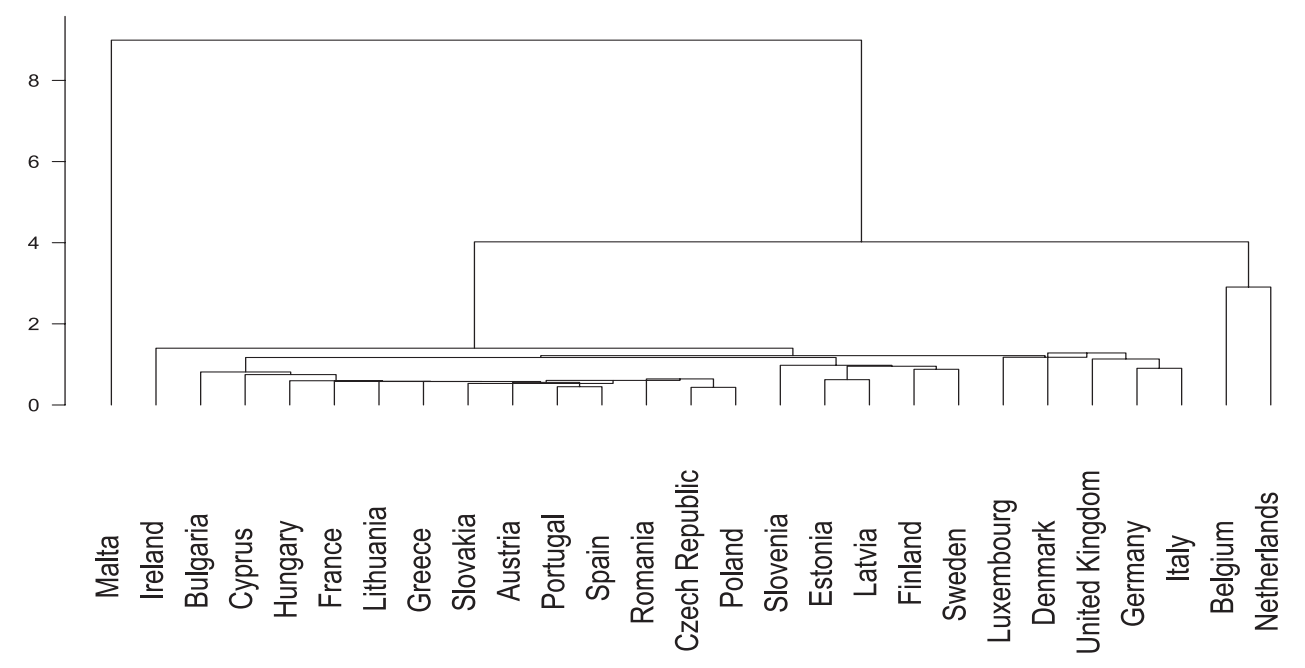

Fig. 2. Dendogram in the European Union. 
Table 2. Cluster centroid for European Union variables.

\begin{tabular}{|c|c|c|c|c|c|c|c|}
\hline Cluster & 1 & 2 & 3 & 4 & 5 & 6 & 7 \\
\hline $\begin{array}{c}\text { Population } \\
\text { density }\end{array}$ & 98.86 & 41.60 & 195.40 & 63.70 & 348.30 & 486.20 & $1,380.00$ \\
\hline Forest area & 0.32 & 0.61 & 0.23 & 0.11 & 0.22 & 0.11 & 0.34 \\
\hline $\mathrm{CO}_{2}$ & 0.76 & 0.38 & 2.32 & 0.68 & 4.13 & 6.10 & 1.32 \\
\hline Sulphur O. & 1.79 & 0.44 & 1.01 & 0.47 & 2.47 & 1.12 & 24.82 \\
\hline Nitrogen O. & 2.07 & 0.85 & 4.19 & 1.29 & 6.88 & 8.12 & 27.08 \\
\hline Ammonia & 0.70 & 0.32 & 1.48 & 1.54 & 2.15 & 3.69 & 5.12 \\
\hline $\begin{array}{c}\text { Other } \\
\text { compounds }\end{array}$ & 1.55 & 0.83 & 2.89 & 0.75 & 3.50 & 4.53 & 7.47 \\
\hline Fresh water & 0.05 & 0.03 & 0.05 & 0.01 & 0.20 & 0.31 & 0.11 \\
\hline
\end{tabular}

emission values (these characteristics are magnified in the case of Malta, which represents an extreme case within the EU). Population density is a very important factor with respect to the other variables; a high population density directly impacts air pollution and indirectly on the forest area [33]. $\mathrm{CO}_{2}$ levels are positively related to emissions of $\mathrm{NO}_{2}$, ammonia, and other compounds, but are inversely related to emissions of sulphur oxides.

\section{Conclusions}

In summary, different patterns of behaviour can be found among EU countries for atmospheric indicators that impact the environment (Fig. 3). Among the clusters formed by a single country, the case of Malta stands out because of its bad records: the population density is high, and emissions of sulphur oxides, nitrogen oxides, ammonia, and other compounds are extreme. A similar

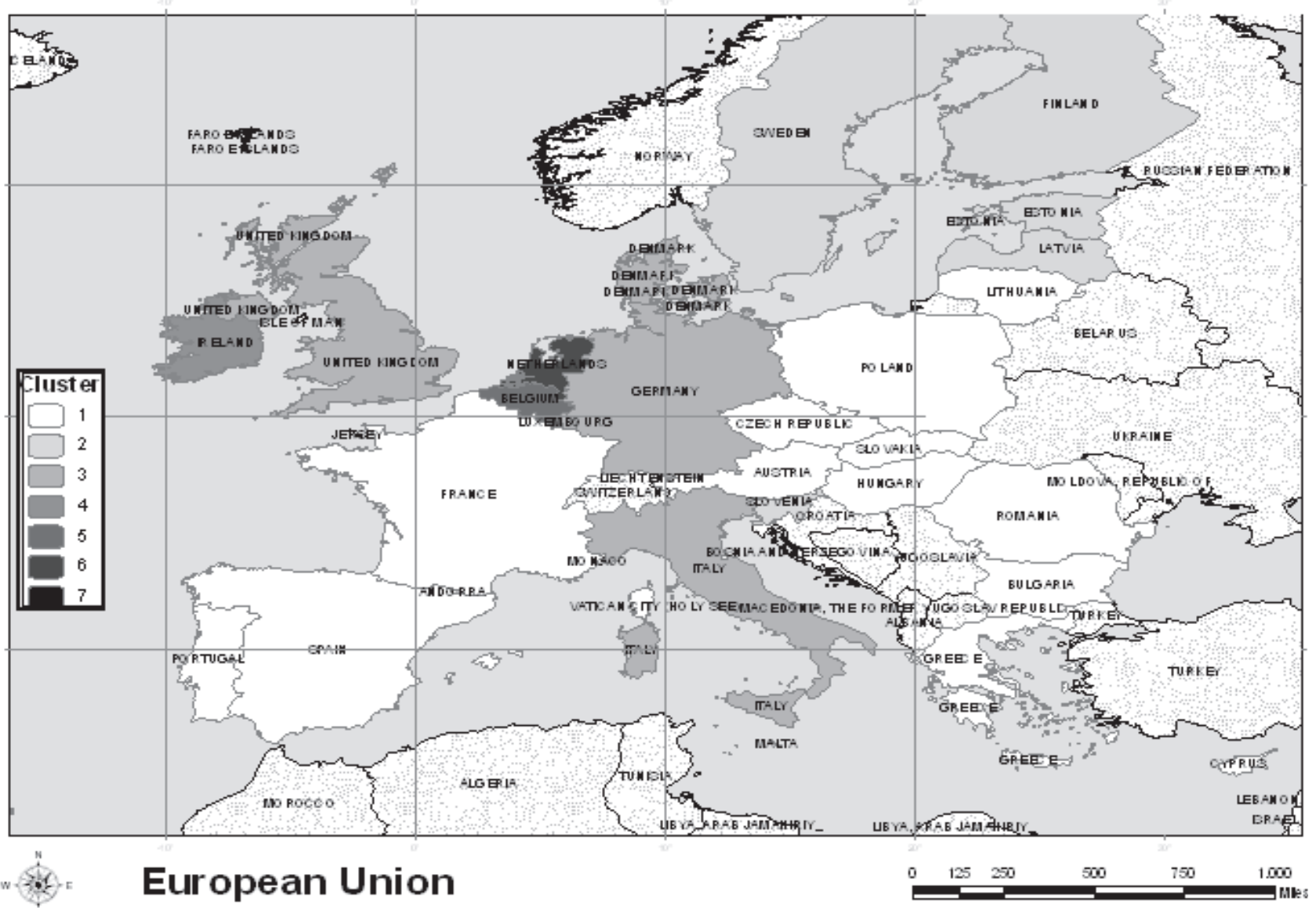

Fig. 3. Cluster for EU membership by each country. 
pattern, although less extreme, is found in the Netherlands and in Belgium, where, in addition, levels of $\mathrm{CO}_{2}$ and nitrogen oxide are high. However, these two countries present levels of freshwater extraction that are well above the EU average. As mentioned above, the outcomes for Malta, the Netherlands, and Belgium are in accordance with those described in the 2015 United Nations annual report, which states that concentrations of particulate matter and nitrogen oxides exceed the EU limit values.

The mean EU value could be associated with cluster No. 1, while No. 2 would be considered as more acceptable, being represented by a relatively low population density, considerable forest cover, and low levels of emissions to the atmosphere. Cluster No. 3 consists of countries with below-average results, with high population densities, low levels of forest area, and relatively high levels of emissions.

The analysis performed allows us to establish groups of countries according to their emissions. Regardless of these results, very high overall quantities are observed. Global harmonization of government emission control policies is therefore necessary.

\section{Acknowledgements}

This research is financed by the Vice-Rector's Office for Political Science and Research at the University of Granada through the project "Social-Labour Statistics and Demography" (30.BB.11.1101) at the Faculty of Labour Sciences.

\section{References}

1. ECOLOGIC INSTITUTE. Final Report for the Assessment of the 6th Environment Action Programme, Brussels, 2011. Available online: http://www.ieep.eu/assets/790/6EAP final_report.pdf

2. EUROPEAN ENVIRONMENTAL BUREAU, EEB. Future of EU Environmental Policy: Towards the 7th Environmental Action Programme, Federation of Environmental Citizens Organisations, EEB, Belgium, 2010. Available online: http://www.eeb.org/index.cfm/activities/sustainability/7thenvironmental-action-programme/

3. UNITED NATIONS ENVIRONMENT PROGRAMME, UNEP. Assessing the Environmental Impacts of Consumption and Production: Priority Products and Materials, A Report of the Working Group on the Environmental Impacts of Products and Materials to the International Panel for Sustainable Resource Management, 2010.

4. QUEROL X. Air quality, particulate matter and metals. Spanish Journal of Public Health, 82, 447, 2008 [In Spanish].

5. EUROPEAN ENVIRONMENT AGENCY. Air pollution impacts from carbon capture and storage, EEA Technical report, 2011.

6. ECHARRI L. Life and environment sciences. Teide: Spain, 1998 [In Spanish]

7. SAMARANDA C., GAVRILESCU M. Migration and fate of persistent organic pollutants in the atmosphere- a modelling approach. Environmental Engineering and Management Journal, 7 (6), 743, 2008.

8. GUILLET R. Energy and Economical Growth: Overview and Global Challenges. Environmental Engineering and Management Journal, 9 (10), 1357, 2010.

9. QUESADA J.M., HUETE M.D., DEL-MORAL M.J., NAVARRETE E., ROSALES M.J. Impact of Environmental and Human Factors on Rural Fire Occurrence. Environmental Engineering and Management Journal, 10 (12), 1857, 2011.

10. HALEK F., KYANPOUR M., PIRMORADI A., KAVOUSI A. Estimation of Urban Suspended Particulate Air Pollution Concentration. International Journal of Environmental Research, 4 (1), 161, 2010.

11. ZOU B., ZHAN F.B., ZENG Y., YORKE CH., LIU X. Performance of Kriging and EWPM for Relative Air Pollution Exposure Risk Assessment. International Journal of Environmental Research, 5 (3), 769-, 2011.

12. EUROSTAT, European Commission. Air Pollution. Technical report, 2012. Available online: http://appsso.eurostat. ec.europa.eu/nui/show.do?dataset=nv_air_emis\&lang=en

13. EUROSTAT, European Commission. Demographic balance and crude rates. Technical report, 2012. Available online: http://appsso.eurostat.ec.europa.eu/nui/ show.do?dataset $=$ demo_gind\&lang=en

14. EUROSTAT, European Commission. Water use balance. Technical report, 2012. Available online: http://appsso. eurostat.ec.europa.eu/nui/show.do?dataset=env_ watqsum\&lang=en

15. THE WORLD BANK. Indicators: Forest area. Technical report, 2012. Available online: http://datos.bancomundial. org/indicador/AG.LND.FRST.K2

16. LIEFGRENN D. Long-range air pollution: A threat to European forests, Unasylva, 37 (149), 14, 1985.

17. EUROPEAN UNION. Member countries of the EU. Available online: https://europa.eu/european-union/abouteu/countries en

18. REY S.J., MONTOURI B.D. U.S. regional income convergence: a spatial econometric perspective. Regional Studies, 33, 145-156, 1999.

19. SOKAL R.R., ODEN N.L. Spatial autocorrelation in biology 1. Methodology. Biological Journal of the Linnean Society, 10, 199, 1978.

20. TOBLER W. Cellular geography. In Philosophy in Geography, Gale, S. and Olsson, G. Eds., Reidel: Dordrecht, 379, 1979.

21. UPTON G.J., FINGLETON B. Spatial data analysis by example, volume1: Point pattern and quantitative data, Wiley: Toronto, 1985.

22. CLIFF A. D., ORD J.K. Spatial processes: Models and Applications, Pion Limited: London, 1981.

23. MORAN P.A.P. The interpretation of statistical maps. Journal of the Royal Statistical Society B, 10, 243, 1948.

24. MORAN P.A.P. Notes on continuous stochastic phenomena. Biometrika, 37, 17, 1950.

25. ESRI, Environmental Systems Research Institute. ArcGIS 9 Software products, 2004. Available online: http://www.esri. $\mathrm{com} /$

26. EUROPEAN PARLIAMENT. Notice to members: CM $\backslash 814286$ EN.doc, 2010. Available in http://www. europarl.europa.eu/RegData/commissions/peti/ communication/2010/392329/PETI CM(2010)392329 EN.pdf

27. PEÑA J. Geographic Information Systems Applied to Land Management. University Club of Alicante: Spain, 2006 [In Spanish]. 
28. UNITED NATIONS. Environment Programme: Air Quality Policy Catalogue Individual Country Reports. Report 5, 2015.

29. SAMMUT J.M. Time to wake up (Malta). Social Watch National reports 136, 2012. Available in http://www. socialwatch.org/sites/default/files/malta2012_eng.pdf

30. MITCHELL A. The ESRI Guide to GIS Analysis: Modeling Suitability, Movement, and Interaction. Volume 3. Esri Press: United States, 2012.

31. KAUFMAN L., ROUSSEEUW P. Finding Groups in Data: An Introduction to Cluster Analysis. Wiley: New Jersey, 2008.
32. R DEVELOPMENT CORE TEAM. R: A Language and Environment for Statistical Computing. R Foundation for Statistical Computing: Vienna, Austria, 2012. Available online: http://www.R-project.org.

33. LEPETU J., ALAVALAPATI J., NAIR P.K. Forest dependency and its implication for protected areas management: A case study from Kasane Forest Reserve, Botswana. International Journal of Environmental Research, 3, 525-536, 2009. 
